\title{
Individual and interactive effects of salinity and initial fish density on a salt marsh assemblage
}

\author{
Christopher L. Rowe*, William A. Dunson \\ Department of Biology, The Pennsylvania State University, 208 Mueller Laboratory, University Park, Pennsylvania 16802, USA
}

\begin{abstract}
We used static outdoor mesocosms (155 l) to study the effects over $60 \mathrm{~d}$ of 3 levels of total fish density and 3 levels of salinity $(1,5$, and $32 \mathrm{ppt}$ ) on growth and survival of juvenile fish (silversides Menidia beryllina, hereafter referred to as Menidia; and sheepshead minnows Cyprinodon variegatus, hereafter Cyprinodon) that are common to salt marsh pools of the eastern United States. Interactions between these 2 species and rainwater killifish Lucania parva (hereafter Lucania) were also examined. There was a general decline in the rate of growth and the percentage survival with increasing fish density. Salinity and density interacted significantly such that the percentage survival of Cyprinodon was lowest in the high salinity-high density treatment compared to most other treatments. It did not appear that Cyprinodon or Menidia interacted strongly with Lucania, since growth and survival of the former 2 species were independent of abundance of Lucania. Fish simultaneously maintained in permeable enclosures in the field generally had similar or lower rates of growth than those in mesocosms, indicating that conditions in the mesocosms were not inherently more stressful than conditions in natural salt marsh pools. It appears that this fish assemblage is regulated in part by both a biotic (density/competition) and an abiotic factor (salinity). We conclude that, under circumstances in which conditions are severe due to high total fish density, a level of salinity that appears to be otherwise inconsequential may have important implications for community structure by impacting survival of one species.
\end{abstract}

KEY WORDS: Competition Cyprinodon-Lucania $\cdot$ Menidia $\cdot$ Mesocosms

\section{INTRODUCTION}

Pools of the high salt marsh along the mid-Atlantic coast of the U.S. are abiotically rigorous, support a limited and characteristic assemblage of fish and invertebrates during larval development, and are important sites for recruitment of organisms to neighboring habitats. These small pools $\left(-1.5\right.$ to $100 \mathrm{~m}^{2}$ surface area) are located in the highest portion of the salt marsh (where Spartina patens is the dominant vascular plant) and are infrequently flooded by abnormally high tides, thus remaining static for long periods of time (several months in many cases; authors' pers. obs.). During tidal isolation, hydrology is determined by precipitation, freshwater runoff inputs, and evapotranspiration,

\footnotetext{
- Present address: University of Georgia, Savannah River Ecology Laboratory, Drawer E, Aiken, South Carolina 29802, USA. E-mail: rowe@srel.edu
}

resulting in a wide range of salinity $(2$ to $>60 \mathrm{ppt}$; authors' pers. obs.) and depth, depending upon the relative amounts of input and loss of fresh water.

The biota of the pools is primarily derived from subtidal habitats and is either transported into the pools during tidal flooding or results from reproduction of adults on the marsh during flood tides. Possibly as a result of the rigorous conditions, a limited assemblage of larval fish and macroinvertebrates is common to the pools (Fig. 1, see also Appendix 1). Besides the wide range in potential abiotic stresses, these organisms may also experience severe food limitations due to limited tidal inputs of resources and extremely high animal densities during times of low water (as high as 156 fish $\mathrm{m}^{-2}$ i Appendix 1). Provided that complete drying does not occur prior to a liberating high tide, these organisms are recruited from the nursery pools to the subtidal habitat where they constitute important resources for other trophic systems (Conover \& Ross 


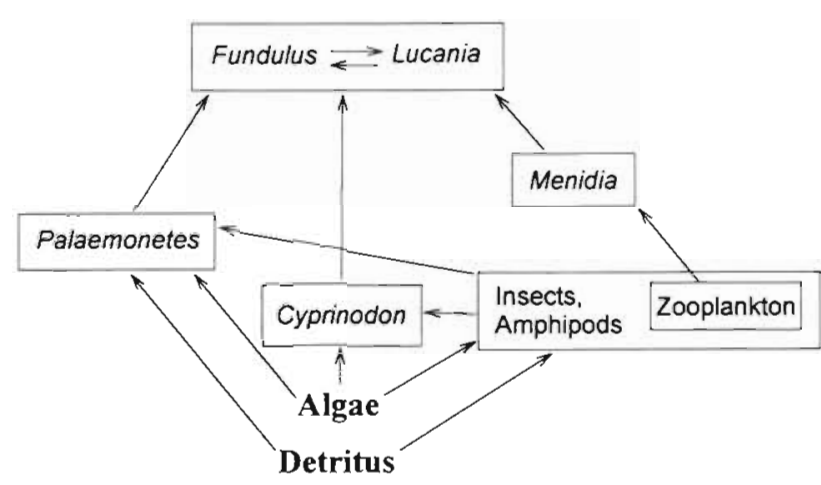

Fig. 1. Hypothesized food web for the assemblage of estuarine fish and invertebrates common to high salt marsh pools of the mid-Atlantic coast of the U.S. 'Fundulus' and 'Palaemonetes' refer to the mummichog $F$. heteroclitus and the grass shrimps $P$. pugio and $P$. vulgaris, common components of the assemblages that were not included in this experiment

1982, Kneib 1986, 1987). Thus these communities may represent an important trophic link between the terrestrial and marsh habitats and neighboring open water systems.

A general assemblage of 4 species of fish and several invertebrates is widely distributed in high marsh ponds along the seaside of the eastern shore of Virginia, USA. (Fig. 1). An interesting property of this assemblage is the variation among sites in the relative proportions of each species. Certain ponds may be completely dominated by sheepshead minnows Cyprinodon variegatus (hereafter referred to as Cyprinodon) or rainwater killifish Lucania parva (hereafter referred to as Lucania), while others have a more equitable mixture of these and several other species (Dunson et al. 1993). The reason for such patchiness is as yet unknown, although it has been suggested that variation in relative tolerance to abiotic stress could be a major factor (Dunson et al. 1993, Dunson \& Travis 1994). Other conditions in the marsh pools can also be spatially and temporally heterogeneous, depending for example on such factors as the potential for competitive or predatory interactions and the presence of cover in the form of vegetation. Thus, investigations concerning the characteristics of marsh pool communities should consider variables of both abiotic and biotic natures.

The purpose of the present study was to examine some of the parameters that might be involved in regulating growth and survival of fish of high salt marsh ponds, which ultimately may influence the structure of the community inhabiting these environments. The high intertidal zone is an area characterized by low species richness and high environmental harshness. A better understanding of the factors that regulate communities in this zone would thus be of interest in clarifying the interactive role of abiotic rigor and biotic forces (Dunson \& Travis 1991). Such information would also be useful for evaluating the effect of anthropogenic influences on the estuary, since runoff from the land often enters the intertidal zone. Furthermore, the relative isolation of high marsh ponds from tidal influences greatly simplifies the techniques needed to simulate this community so that controlled, replicated experiments can be conducted. We applied here an outdoor static mesocosm procedure historically used in the study of amphibian communities in small fresh water ponds (see review by Rowe \& Dunson 1994).

Our general hypothesis was that juvenile fish assemblages in high salt marsh pools are influenced differentially by the specific combination and relative strengths of each type of stress (biotic or abiotic). Based upon our observations in the field, we chose one abiotic variable (salinity) and one biotic variable (total fish density) that vary widely temporally or spatially to test for their individual and interactive effects on growth and survival of fish in a representative marsh pool assemblage. We specifically hypothesized that: (1) increased fish density would lead to decreased growth and survival of fish, and (2) salinity (1 to $32 \mathrm{ppt}$ ) would have little direct effect on these euryhaline fish.

\section{MATERIALS AND METHODS}

Experimental design. We used 36 outdoor static mesocosms to test for the effects of initial total fish density ( 3 levels) and salinity ( 3 levels) in a factorial experiment on growth and survival of Menidia beryllina (hereafter referred to as Menidia) and Cyprinodon over a period of $60 \mathrm{~d}$. Treatments were assigned according to a randomized block design with 4 replicates per treatment. We also used 24 permeable enclosures placed in 6 field sites to compare growth of fish in mesocosms with in situ growth rates. Quantitative surveys for diversity and abundance of fish and invertebrates in field sites that differed abiotically (hydrologically) and biotically (vegetationally) were also conducted.

Design of mesocosms. Mesocosms were constructed of plastic $102 \mathrm{~cm}$ diameter wading pools which held approximately $155 \mathrm{l}$ when filled to a depth of $19 \mathrm{~cm}$. They were filled with either sea water from Queen Sound Channel, Chincoteague Bay, Virginia (32 ppt), or a mixture of fresh water from a tidal fresh water creek (Little Mosquito Creek, Virginia) and Chincoteague Bay water to give 3 levels of salinity: 32, 5, and $1 \mathrm{ppt}$ ( $14 \mathrm{mM} \mathrm{Na}$ ). The mesocosms were arranged on a concrete pad at the Wallops Island Marine Science Consortium, Wallops Island, Virginia. A greenhouse shade cloth ( $-60 \%$ shade) was suspended over the tanks to avoid overheating. Each pool was covered 
with a clear plastic lid to minimize influences of precipitation or evaporation and was vented to allow air circulation.

Biotic components. Eighteen days prior to addition of test animals to mesocosms, we added equal amounts of dry eelgrass Zostera marina and algae (and attached biota) to all pools. Algae added to low salinity treatments ( 1 and 5 ppt) was collected from a low salinity ( $\sim 4 \mathrm{ppt}$ ) impoundment on Chincoteague Island, Virginia, and was primarily Cladophora spp. Algae added to sea water tanks was collected in Oyster Bay, Virginia (32 ppt, $-0.5 \mathrm{~km}$ from low salinity site) and was primarily Cladophora spp., but a small amount of Ulva lactuca was also present. On the following day we added an equal volume of a suspension of plankton and juvenile insects (corixids) to all pools. This suspension was a mixture of organisms collected from 2 salt marsh ponds by dipnetting ( $\sim 0.2 \mathrm{~mm}$ mesh size). Zooplankton introduced to the pools with water and algae were primarily ostracods and copepods.

Over a 3 d period at the start of the experiment (Day -1 to Day 1 ) we added juvenile fish ( 1 species $\mathrm{d}^{-1}$ ) to all pools. We collected Lucania and Menidia from 2 low salinity (1 to $4 \mathrm{ppt}$ ) ponds; we collected Cyprinodon from 1 brackish pond ( $\sim 14 \mathrm{ppt})$ and 1 low salinity pond ( $\sim 1 \mathrm{ppt}$ ). We acclimated all fish to the target salinity levels over 24 to $48 \mathrm{~h}$ by gradually increasing or decreasing salinity in laboratory holding tanks.

We used 3 overall nominal fish densities, $0.125,0.25$,

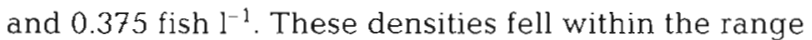
of densities that we measured in several field sites (Appendix 1). We added the fish in a 1:1:2 ratio of Cyprinodon:Lucania:Menidia. We chose this ratio based upon the relative abundances of species that we had previously observed in early summer in some open-water salt marsh ponds and shallow subtidal sites, and on availability of juveniles. However, relative abundances of fish were widely variable temporally and spatially across different sites. To estimate the average initial (Day 1) sizes of fish we measured wet mass and total length (TL) of 10 specimens of each species haphazardly drawn from the pool of animals to be added to the mesocosms (mean $\pm \mathrm{SE}$ : Menidia mass $0.002 \pm 0.001 \mathrm{~g}, \mathrm{TL} 8.0 \pm 0.6 \mathrm{~mm}$; Cyprinodon mass $0.011 \pm 0.002 \mathrm{~g}$, TL $10.2 \pm 0.5 \mathrm{~mm}$; Lucania mass 0.012 $\pm 0.002 \mathrm{~g}$, TL $10.9 \pm 0.6 \mathrm{~mm}$ ). Fish that were measured were not used in the experiments since juveniles of such small size are easily damaged by handling.

After $60 \mathrm{~d}$, all organisms were collected by filtering the water through a $2 \mathrm{~mm}$ mesh and sorting through detritus by hand. Final wet mass and TL were measured. Instantaneous growth rates were calculated as $g=\ln \left(X_{\mathrm{F}} / X_{0}\right) / T$, where $X_{\mathrm{F}}$ is final mass or length and $X_{0}$ is initial mass or length, and $T$ is time (60 d) (Ricker 1979).
Monitoring of abiotic parameters. We measured salinity in the medium and high treatments biweekly with a hand-held refractometer. Since the accuracy of this instrument below 2 ppt was questionable, we measured [ $\mathrm{Na}$ ] in the lowest salinity (1 ppt) treatment with a flame emission photometer. Salinity did not require adjustment during the experiment. We measured temperature at the surface $(2.5 \mathrm{~cm}$ depth) and bottom when salinity measurements were made. We measured changes in [dissolved oxygen] (2.5 cm depth) with a portable meter (YSI model 51B) from near sunrise until several hours following sunset on 3 occasions for comparison with [dissolved oxygen] measured in field sites at approximately the same time (within $30 \mathrm{~min}$ ).

Enclosures. We constructed enclosures of $19 \mathrm{l}$ gray polyethylene buckets from which an area was cut from the sides and tops and replaced with $2 \mathrm{~mm}$ mesh fiberglass screening. Four enclosures were placed in each of 6 sites ( 3 intertidal ponds, 1 impoundment, 2 shallow subtidal sites), and each enclosure received 4 Menidia, 2 Cyprinodon, and 2 Lucania larvae from the pool of organisms collected for mesocosm studies. At 5 to $7 \mathrm{~d}$ intervals enclosures were gently scrubbed to remove fouling organisms from the outside of the screen panels. Some enclosures were damaged while in the field and were excluded from analyses. Contents were removed from enclosures after 29 to $60 \mathrm{~d}$ in the field. This discrepancy in the amount of time that the enclosures remained in the field was due to declining water levels in some intertidal pools that necessitated early removal.

Field surveys. In April through September 1993, we conducted surveys for abundance and diversity of fish and macroinvertebrates at several field sites, including salt marsh ponds, man-made impoundments, and shallow subtidal areas. These surveys were conducted in order to validate our choices of total fish densities used in mesocosms and to provide information for designing future studies. We used a square box sampler $(60 \times 60$ $\times 60 \mathrm{~cm}$ ), similar in design to that described by Kushlan (1981), which was thrown from 1 to 12 times (usually 4) at each site. The contents were removed by repeatedly sweeping a close-fitting net ( $2 \mathrm{~mm}$ mesh) through the enclosed water column, vegetation, and detritus until 3 successive sweeps yielded no organisms. Data from these surveys are summarized in Appendix 1.

Statistical analyses. In several tanks we found more Lucania than had been intentionally introduced, so this species was dropped from analyses for growth or survival. We used ANOVA to determine if the number of excess Lucania (transformed by square roots) was related to a particular treatment. Since this parameter was found to be related to salinity, we included the number of Lucania found in each tank as a covariate 
for analyses of effects of density and salinity on growth and survival of other species using ANCOVA. When faced with empty cells we employed the general linear model approach to ANOVA or ANCOVA (Minitab 1989). Prior to all analyses, data were checked for normality by comparing correlations between data (raw and transformed) and normal scores (values expected under normality), which is similar to the Shapiro-Wilk test for normality (Minitab 1989). Data were checked for homogeneity of variance with Hartley's test (Neter et al. 1990). Proportional data were transformed by the arcsine transformation (Neter et al. 1990). Following significant results from ANCOVA we used the Tukey or TukeyKramer procedure for multiple comparisons to determine the particular levels of a factor that differed. Since we observed reproduction of Cyprinodon and Lucania in nearly half of the tanks, we used ANOVA to compare total number of offspring (square root transformed) across treatments. We used ANOVA to test for site-specific differences in survival and growth rates of fish held in enclosures, and to compare growth of fish in enclosures to growth in mesocosms of each initial level of density.

We set our experiment-wide Type I error rate at $\alpha=$ 0.05 and adjusted it downward by dividing by the number of simultaneous analyses conducted (sequential Bonferroni adjustment; Rice 1989). For each table of statistical results for a particular response variable, 4 separate $p$-values were calculated (one each for covariate, density, salinity, and density $\times$ salinity). Using the sequential Bonferroni method, these values were ordered from smallest to largest and compared to adjusted values of $\alpha=0.05 / 4,0.05 / 3,0.05 / 2$, and $0.05 / 1$; p-values greater than the adjusted $p$-value were declared non-significant (Rice 1989).

\section{RESULTS}

\section{Properties of the mesocosms}

Salinity remained quite stable throughout the experiment (mean \pm SE: 'high' $31.7 \pm 0.4$ ppt; 'medium' $4.7 \pm$ 0.2 ppt; 'low' $\sim 1 \mathrm{ppt},=14.4 \pm 0.2 \mathrm{mM} \mathrm{Na}$ ). Surface temperatures remained below $38^{\circ} \mathrm{C}$, and bottom temperatures did not exceed $34^{\circ} \mathrm{C}$. Minimum /dissolved oxygen] occurred just prior to sunrise, and had a range of 3.7 to $4.0 \mathrm{mg} \mathrm{l}^{-1}$ in $1 \mathrm{ppt}$ tanks, 2.4 to $2.5 \mathrm{mg} \mathrm{l}^{-1}$ in $5 \mathrm{ppt}$ tanks, and 1.0 to $1.5 \mathrm{mg} \mathrm{l}^{-1}$ in $32 \mathrm{ppt}$ tanks. Three natural salt marsh ponds (salinity 22 to $35 \mathrm{ppt}$ ) that we measured $30 \mathrm{~min}$ following the pre-sunrise tank measurements had a dissolved oxygen range of 0.4 to $1.0 \mathrm{mg} \mathrm{l}^{-1}$. Maximum [dissolved oxygen] occurred in late afternoon (16:30 to $17: 30 \mathrm{~h}$ ) and had a range of 8.7 to $11.6 \mathrm{mg} \mathrm{l}^{-1}$ in $1 \mathrm{ppt}$ tanks, 9.9 to $12.6 \mathrm{mg} \mathrm{l}^{-1}$ in $5 \mathrm{ppt}$ tanks, 3.0 to $8.9 \mathrm{mg} \mathrm{l}^{-1}$ in $32 \mathrm{ppt}$ tanks, and 6.0 to $8.4 \mathrm{mg} \mathrm{l}^{-1}$ in natural ponds. Algal growth, although not quantified, appeared to be lower in 32 ppt treatments than in those of lower salinity.

\section{Results from field enclosures}

Growth rates (in mass) for 3 species of fish placed together in permeable enclosures in 6 field sites are shown in Table 1. Lucania grew significantly better in subtidal sites than in brackish or high salinity marsh pools $\left(F_{2,8}=8.53, \mathrm{p}=0.010\right)$, whereas growth of $C y$ prinodon and Menidia were independent of location $\left(F_{2,12}=0.67, \mathrm{p}=0.530\right.$ and $F_{2,4}=1.93, \mathrm{p}=0.259$, respec tively). Growtb of Cyprinodon was greater in low density and medium density mesocosms than in field enclosures, but there was no difference between enclosures and high density mesocosms $\left(F_{3.47}=21.22\right.$, $\mathrm{p}<0.001)$. Growth of Menidia did not differ between mesocosms and enclosures.

\section{Effects of treatments on survival and growth}

Survival of both Cyprinodon and Menidia was impacted by initial density (Table 2). A greater proportion of introduced Cyprinodon survived when overall density was at 0.125 or 0.25 fish $\mathrm{l}^{-1}$ than at

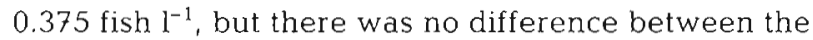
lower 2 densities (Table 3). Survival of Menidia differed among all densities; the greatest proportion of those introduced survived in the low density treatment and the least in the high density treatment (Table 3).

Growth (both in terms of change in mass and length) of Cyprinodon and Menidia was significantly

Table 1. Rates of instantaneous growth $\left(\mathrm{d}^{-1}\right)$ in mass ( $\mathrm{g}$ ) of fish in enclosures. Values are means $\pm 1 \mathrm{SE}$ (no. of replicates)

\begin{tabular}{|c|c|c|c|}
\hline $\begin{array}{l}\text { Duration } \\
\text { (d) }\end{array}$ & $\begin{array}{l}\text { Cyprinodon } \\
\text { variegatus }\end{array}$ & $\begin{array}{l}\text { Menidia } \\
\text { beryllina }\end{array}$ & $\begin{array}{l}\text { Lucania } \\
\text { parva }\end{array}$ \\
\hline \multicolumn{4}{|c|}{ Enclosures in 3 high salmity intertidal ponds $(31-51 \mathrm{ppt})$ : } \\
\hline $29-42$ & $\begin{array}{c}0.048 \pm 0.002 \\
(7)\end{array}$ & $\begin{array}{c}0.037 \pm 0.004 \\
(2)\end{array}$ & $\begin{array}{c}0.022 \pm 0.005 \\
(4)\end{array}$ \\
\hline \multicolumn{4}{|c|}{ Enclosures in 1 brackish intertidal impoundment ( $2-4 \mathrm{ppt}$ ): } \\
\hline 45 & $\begin{array}{c}0.050 \pm 0.001 \\
\text { (4) }\end{array}$ & $\begin{array}{c}0.045 \pm 0.011 \\
(2)\end{array}$ & $\begin{array}{c}0.031 \pm 0.001 \\
\text { (4) }\end{array}$ \\
\hline \multicolumn{4}{|c|}{ Enclosures in 2 subtidal areas $(28-32 \mathrm{ppt})$ : } \\
\hline $59-60$ & $\begin{array}{c}0.048 \pm 0.001 \\
(4)\end{array}$ & $\begin{array}{c}0.051 \pm 0.002 \\
\text { (3) }\end{array}$ & $\begin{array}{c}0.044 \pm 0.001 \\
\text { (3) }\end{array}$ \\
\hline
\end{tabular}


Table 2. Results of ANCOVA comparing survival and growth of Cyprinodon variegatus and Menidia beryllina under 3 levels of salinity and 3 levels of density. "Indicates significance following sequential Bonferroni adjustment

\begin{tabular}{|c|c|c|c|c|c|c|}
\hline Factor & \multicolumn{2}{|c|}{ Survival } & \multicolumn{2}{|c|}{ Growth (mass) } & \multicolumn{2}{|c|}{ Growth (length) } \\
\hline \multicolumn{7}{|c|}{ Cyprinodon variegatus } \\
\hline Covariate (Lucania) & $F_{1,26}=3.80$ & $p=0.062$ & $F_{1,26}=0.38$ & $p=0.543$ & $F_{1,26}=1.04$ & $p=0.317$ \\
\hline Density & $F_{2,26}=13.44$ & $\mathrm{p}<0.001^{\circ}$ & $F_{2,26}=31.45$ & $p<0.001^{\circ}$ & $F_{2,26}=38.96$ & $p<0.001^{\circ}$ \\
\hline Salinity & $F_{2.26}=0.64$ & $p=0.535$ & $F_{2,26}=1.40$ & $\mathrm{p}=0.265$ & $F_{2,26}=1.01$ & $p=0.376$ \\
\hline Density $\times$ Salinity & $F_{4,26}=3.94$ & $p=0.012^{\circ}$ & $F_{4,26}=0.22$ & $p=0.923$ & $F_{4,26}=0.23$ & $p=0.919$ \\
\hline \multicolumn{7}{|l|}{ Menidia beryllina } \\
\hline Covariate (Lucania) & $F_{1.26}=0.30$ & $p=0.586$ & $F_{1.19}=2.39$ & $p=0.139$ & $F_{1.19}=1.99$ & $\mathrm{p}=0.175$ \\
\hline Density & $F_{2,26}=12.91$ & $p<0.001^{\circ}$ & $F_{2.19}=9.74$ & $p=0.001^{\circ}$ & $F_{2,19}=13.04$ & $\mathrm{p}<0.001^{\circ}$ \\
\hline Salinity & $F_{2,26}=0.47$ & $p=0.629$ & $F_{2,19}=1.82$ & $\mathrm{p}=0.189$ & $F_{2,19}=1.34$ & $p=0.285$ \\
\hline Density $\times$ Salinity & $F_{4,26}=1.52$ & $p=0.227$ & $F_{4,19}=2.47$ & $\mathrm{p}=0.079$ & $F_{4.19}=2.71$ & $p=0.061$ \\
\hline
\end{tabular}

Table 3. Effects of initial fish density (no. total fish $\mathrm{l}^{-1}$ ) on survival $(\%)$ and growth $\left(\mathrm{d}^{-1}\right)$ of Cyprinodon variegatus and Menidia beryllina. Values are means $\pm 1 \mathrm{SE}$. Different trailing letters within a column indicate those levels which differed significantly following multiple comparisons. Data for survival were transformed by arcsines prior to analysis

\begin{tabular}{|c|c|c|c|c|c|c|}
\hline \multirow[t]{2}{*}{ Density } & \multicolumn{3}{|c|}{ Cyprinodon variegatus } & \multicolumn{3}{|c|}{ Menidia beryllina } \\
\hline & Survival & Growth (mass) & Growth (length) & Survival & Growth (mass) & Growth (length) \\
\hline 0.125 & $\begin{aligned} 99.9 & \pm 3.9 a \\
N & =12\end{aligned}$ & $\begin{aligned} 0.059 & \pm 0.001 \mathrm{a} \\
\mathrm{N} & =12\end{aligned}$ & $\begin{aligned} 0.017 & \pm 0.001 \mathrm{a} \\
\mathrm{N} & =12\end{aligned}$ & $\begin{aligned} 77.5 & \pm 5.4 \mathrm{a} \\
\mathrm{N} & =12\end{aligned}$ & $\begin{aligned} 0.052 & \pm 0.002 \mathrm{a} \\
\mathrm{N} & =12\end{aligned}$ & $\begin{aligned} 0.014 & \pm 0.001 \mathrm{a} \\
\mathrm{N} & =12\end{aligned}$ \\
\hline 0.25 & $\begin{array}{c}99.5 \pm 5.5 a \\
N=12\end{array}$ & $\begin{array}{c}0.053 \pm 0.001 b \\
N=12\end{array}$ & $\begin{aligned} 0.015 & \pm 0.001 \mathrm{~b} \\
\mathrm{~N} & =12\end{aligned}$ & $\begin{aligned} 52.1 & \pm 10.3 b \\
N & =12\end{aligned}$ & $\begin{aligned} 0.051 & \pm 0.002 a \\
\mathrm{~N} & =10\end{aligned}$ & $\begin{array}{c}0.014 \pm 0.001 \mathrm{a} \\
\mathrm{N}=10\end{array}$ \\
\hline 0.375 & $\begin{aligned} 95.3 & \pm 5.5 b \\
N & =12\end{aligned}$ & $\begin{aligned} 0.049 & \pm 0.001 \mathrm{c} \\
\mathrm{N} & =12\end{aligned}$ & $\begin{aligned} 0.014 & \pm 0.001 \mathrm{c} \\
\mathrm{N} & =12\end{aligned}$ & $\begin{aligned} 30.0 & \pm 8.2 \mathrm{c} \\
\mathrm{N} & =12\end{aligned}$ & $\begin{array}{c}0.042 \pm 0.002 b \\
N=7\end{array}$ & $\begin{aligned} 0.011 & \pm 0.001 b \\
N & =7\end{aligned}$ \\
\hline
\end{tabular}

affected by initial density (Table 2). Growth of Cyprinodon was greatest at the lowest density, intermediate at the medium density, and least at the highest density (Table 3). Growth of Menidia was greater at low and medium densities than at the highest density (Table 3 ).

There were no main effects of salinity on growth or survival of Cyprinodon or Menidia. However, there was a significant interaction between salinity and density for survival of Cyprinodon (Table 2). Survival of this species was reduced by the high density/high salinity treatment compared to all low density treatments, medium density/low and medium salinity, and high density/medium salinity treatments (Fig. 2).

There were significantly more Lucania (beyond those added intentionally) in the $32 \mathrm{ppt}$ treatment than in the 1 or 5 ppt treatments $\left(F_{2,31}=51.78, p<0.001\right)$, indicating that eggs were present in algae taken from high salinity sites. However, there were no effects of excess Lucania on survival or growth of other species (covariate in Table 2). There was no evidence of accidental introduction for either of the other species of fish.

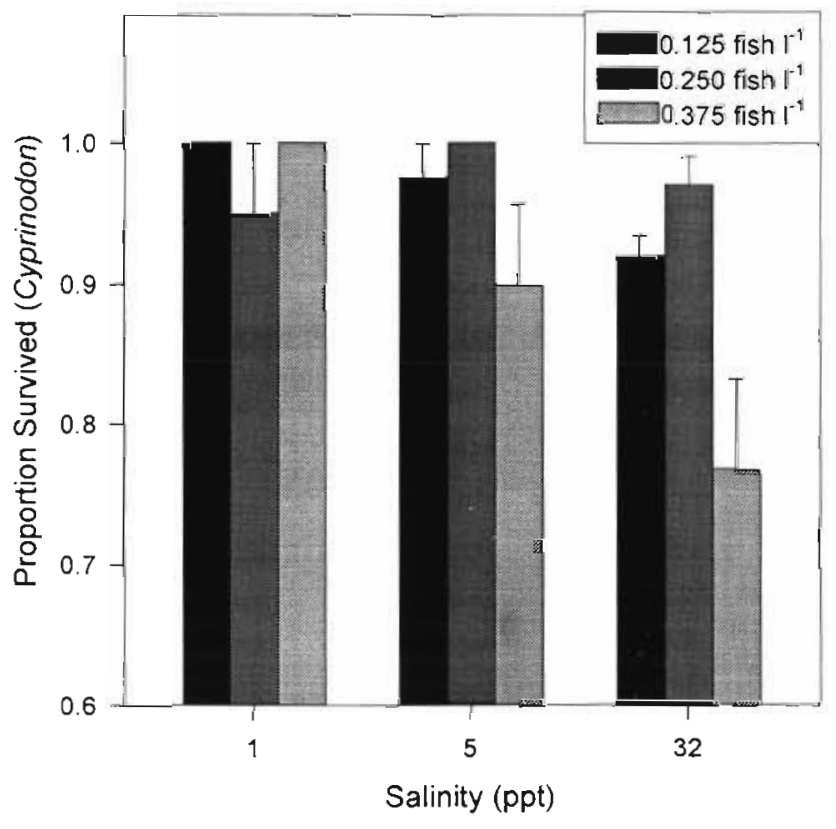

Fig. 2. Interactive effects of initial total fish density and salinity on survival of Cyprinodon variegatus. Values are means $\pm 1 \mathrm{SE}$ 


\section{Reproduction by fish}

Cyprinodon and Lucania reproduced in 16 of the 36 mesocosms $(44 \%)$. We found from 1 to 6 hatchling Cyprinodon and from 1 to 19 hatchling Lucania in these tanks. There was no effect of treatment on total number of offspring collected at the end of the experiment $\left(F_{8.27}=2.81, p=0.021\right)$.

\section{DISCUSSION}

It appears that the $155 \mathrm{I}$ mesocosms provided a suitable environment for fish growth, since 2 of 3 species introduced reproduced in nearly half of the tanks, and reproduction may be the parameter most sensitive to abiotic stress (Dunson \& Travis 1991). Also, growth rates for the fish were similar to or somewhat greater than those which we observed in permeable enclosures placed in the field.

The highest fish density $\left(0.375\right.$ fish $\left.l^{-1}\right)$ reduced the proportion of initially introduced fish that survived and the instantaneous growth rates for both Cyprinodon and Menidia, indicating that food limitations must have been quite severe. These limitations apparently occurred at 2 distinct trophic levels, affecting the facultatively herbivorous Cyprinodon and the zooplanktivorous Menidia (Fig. 1). We have no quantitative estimates of zooplankton abundance following the experiment with which we can address the response of Menidia to increased density. However, it certainly appeared that this species was competing with greater intensities at each higher level of density, either intraspecifically or interspecifically with larval Lucania. In related studies using various combinations of these species and several others (Fig. 1), we have found that inter- and intraspecific interactions can be quite strong, depending upon the composition of the assemblage and relative abundances of each species (Dunson \& Rowe in press). We have also found that predation by adult fish reduces densities of juveniles and results in increased growth rates for the juveniles (C. Rowe \& W. Dunson unpubl. data). This appears to fit the classic model of competitive release resulting from predation on competing species (see Morin 1981).

Dunson \& Rowe (unpubl. data) have observed increased growth rates of Lucania when low salinity favored presence of a predatory insect that preyed upon juvenile fish. This result was attributed to a possible decrease in the intensity of intraspecific competition among fish when population size was decreased by the predator. In the current study, reduced survival of each species at high density did not appear to influence intraspecific competition, since growth rates were reduced at high density as well. This may indicate either that sufficient survivors remained in high density treatments to keep resources at a limiting level, or that the resources that were impacted early in the experiment were not naturally replaced rapidly enough to provide adequate food for surviving larvae. Growth and survival of Cyprinodon and Menidia were density dependent, whereas only in the highest density treatments did we observe an effect of salinity. Thus the primary stress incurred in this experiment was biotic, manifested in competition for resources. However, under the most severe conditions of this variable, the additional stress of an abiotic factor (high salinity) had considerable impact on Cyprinodon.

The mode of action of high salinity on Cyprinodon in high density treatments remains unclear from this experiment, as the effect of high salinity may have been either direct or indirect. All of the fish species used here are euryhaline, and have been shown to be acutely tolerant of all levels of salinity tested here (Dunson et al. 1993) and/or are found naturally in sites of a wide range in salinity (authors' pers. obs.). However the body fluids of tolerant fish are regulated at approximately one third of normal sea water by various energy-requiring processes. Thus Cyprinodon may have experienced an energy deficit due to increased osmoregulatory requirements in high salinity treatments. The deficit was not expressed as an effect on survival when density was low or moderate and food was presumably not limiting.

A variable that appeared to be correlated with salinity was [dissolved oxygen]. While our data regarding this variable are sparse, it appears that [dissolved oxygen] remained somewhat lower in high salinity treatments than in those of other salinity levels. However, [dissolved oxygen] in high salinity mesocosms remained above that in natural ponds in which Cyprinodon commonly occur. Thus, it did not appear that low [dissolved oxygen] associated with high salinity treatments was directly responsible for reduced survival of this species, although we cannot rule out the possibility that low [dissolved oxygen] and high salinity worked in concert to directly impact Cyprinodon.

It is also possible that there was an indirect effect of salinity on Cyprinodon as a result of impacts at a lower trophic level. The importance of indirect effects to community structure was addressed by Strauss (1991). However, the author's consideration of indirect effects due to changing abiotic conditions was limited to those modifications that were ultimately driven by a biotic variable (termed 'environmental' indirect effects; Strauss 1991). Yet the type of indirect effect that may have occurred in this study was an abiotically driven impact on a lower trophic level (macroalgae), which had ramifications at a higher level (Cyprinodon). It appears that the algae Cladophora spp. introduced to 
mesocosms were intolerant in some way of conditions in the 32 ppt treatment, since little was observed in this treatment after $60 \mathrm{~d}$. On the other hand there was a considerable amount of Cladophora spp. remaining in all 1 and 5 ppt tanks following the experiment, regardless of fish density. Thus an impact of high salinity conditions on the macroalgal food source of Cyprinodon could have led to severe enough food limitations in high density treatments to reduce survival of this species. The absence of this interaction for the planktivorous Menidia indicates that the planktonic assemblage probably was not impacted severely by salinity.

Miller \& Dunn (1980) argued that the most successful juvenile fish in estuarine habitats are generalists that exploit available resources and move to other areas or microhabitats when food has been depleted. While this argument may hold true for fish in estuarine environments in which a large number of habitat choices exist, the static nature of salt marsh pools limits the options of organisms to emigrate when resources are limited. Rather, the fish are limited both by the resources initially present in the ponds and the potential responses of the resources to rigors incurred while isolated there.

Weisberg (1986) examined interactions among cooccurring estuarine species of Fundulus and concluded that competition rather than physiological tolerance to stress determined species richness in a given habitat.
Poulin \& FitzGerald (1989) on the other hand concluded that survival and growth of 3 salt marsh sticklebacks were influenced to a greater degree by factors such as salinity, temperature, dissolved oxygen, and water regime than by competitive interactions. While inter- and intraspecific competition are obviously important in salt marsh ponds and some shallow subtidal habitats, indirect influences of abiotic factors may also be of great importance if their effects are manifested elsewhere in the foodweb. Thus, the potential importance to communities of abiotic variables cannot be overlooked simply because they have no observable direct effect on higher trophic levels.

Acknowledgements. We appreciate the help of J. Gentile, $\mathrm{M}$. Donne, L. Nanovic, and M. Perdue who provided technical assistance during this study, and R. Pursell for aid in identifying algae. We are grateful to the faculty and staff of the Wallops Island Marine Science Consortium for allowing us to conduct this study at their facility. A. Guber, C. Bursey, and the students of the 1993 Penn State Marine Science field course aided in collection of algae. C. Paradise and $\mathrm{K}$. Lentz provided editorial comments on a draft of this manuscript. This project was funded in part by grants R817206-01 and R818349-01 from the U.S. Environmental Protection Agency to W.A.D. However, these findings have not been reviewed by this agency and therefore no official endorsement is implied. Final manuscript preparation and editing were aided by contract DE-AC09-76SROO-819 between the University of Georgia and the U.S. Department of Energy.

Appendix 1. Summary of field density estimates for fish and shrimp (Palaemonetes) using throw sampler, 1993. N: no. of sites in which a particular species was found. All fish captured on April 23, 1993 (and most on May 20), were adults (except for several Anguilla elvers). nq: not quantified

\begin{tabular}{|c|c|c|c|c|c|c|c|}
\hline Fish & No. 1 & $1^{-1}$ (range) & $\mathrm{N}$ & No. $\mathrm{m}^{-2}$ (range) & Shrimp & No. $\mathrm{m}^{-2}$ (range) & $\mathrm{N}$ \\
\hline \multicolumn{8}{|c|}{ April $23,1993^{\circ}$. Assateague Island ponds ( 9 ponds; 10 to $30 \mathrm{ppt}$ ) } \\
\hline Cyprinodon & 0.03 & $(0.01-0.08)$ & 5 & $11.94(2.78-13.89)$ & Palaemonetes pugio & $20.5(19-22)$ & 2 \\
\hline Menidia & 0.01 & & 1 & 0.92 & & & \\
\hline Fundulus & 0.007 & $(0.005-0.008)$ & 2 & $1.85(0.92-2.78)$ & & & \\
\hline Lucania & 0.10 & $(0.03-0.19)$ & 8 & $16.91(2.78-36.11)$ & & & \\
\hline Anguilla & 0.025 & $(0.01-0.05)$ & 4 & $4.86(2.78-11.11)$ & & & \\
\hline Total & 0.12 & $(0.02-0.23)$ & 9 & $24.85(5.56-41.67)$ & & & \\
\hline \multicolumn{8}{|c|}{ May $20,1993^{\circ}$. Wallops Island intertidal impoundment (2 ppt) } \\
\hline Lucania & & 0.05 & 1 & 16.11 & & & \\
\hline Total & & 0.05 & 1 & 16.11 & & & \\
\hline \multicolumn{8}{|c|}{ July $22,1993$. Wallops Island intertidal impoundment (5 ppt) } \\
\hline Cyprinodon & & 0.02 & 1 & 2.08 & & & \\
\hline Fundulus & & 0.03 & 1 & 3.47 & & & \\
\hline Lucania & & 1.22 & 1 & 150.00 & & & \\
\hline Anguilla & & 0.02 & 1 & 0.69 & & & \\
\hline Total & & 1.25 & 1 & 156.25 & & & \\
\hline \multicolumn{8}{|c|}{ July $22,1993$. Mainland high marsh pond (46 ppt) } \\
\hline Cyprinodon & & 0.06 & 1 & 4.86 & & & \\
\hline Fundulus & & 0.04 & 1 & 4.17 & & & \\
\hline Lucania & & 0.15 & 1 & 11.11 & & & \\
\hline Total & & 0.26 & 1 & 20.14 & & & \\
\hline
\end{tabular}


Appendix 1 (continued)

\begin{tabular}{|c|c|c|c|c|c|c|}
\hline Fish & No. $l^{-1}$ (range) & $\mathrm{N}$ & No. $\mathrm{m}^{-2}$ (range) & Shrimp & No. $\mathrm{m}^{-2}$ (range) & N \\
\hline \multicolumn{7}{|c|}{ July 26, 1993. Mainland brackish lake ( 7 ppt) } \\
\hline Lucania & 1.16 & 1 & 229.17 & \multirow{4}{*}{$\begin{array}{l}\text { Palaemonetes pugio } \\
\text { and } P \text { vulgaris }\end{array}$} & \multirow[t]{4}{*}{218} & \multirow[t]{4}{*}{1} \\
\hline Fundulus & 0.014 & 1 & 0.69 & & & \\
\hline Anguilla & 0.02 & 1 & 2.08 & & & \\
\hline Total & 1.16 & 1 & 231.25 & & & \\
\hline \multicolumn{7}{|c|}{ August 11, 1993. Coard's Marsh subtidal area (Zostera bed; $32 \mathrm{ppt}$ ) } \\
\hline Lucania & 0.08 & 1 & 50.00 & \multirow{4}{*}{$\begin{array}{l}\text { Palaemonetes pugio } \\
\text { and } P \text {. vulgaris }\end{array}$} & \multirow[t]{4}{*}{$\mathrm{nq}$} & \multirow[t]{4}{*}{1} \\
\hline Sygnathus & 0.01 & 1 & 3.47 & & & \\
\hline Other & 0.01 & 1 & 4.17 & & & \\
\hline Total & 0.09 & 1 & 56.25 & & & \\
\hline \multicolumn{7}{|c|}{ September 22, 1993. Coard's Marsh subtidal area (Zostera bed; 32 ppt) } \\
\hline Lucania & $0.08(0.02-0.13)$ & 2 & $35.42(11.11-59.73)$ & \multirow{3}{*}{$\begin{array}{l}\text { Palaemonetes } \\
\text { vulgaris }\end{array}$} & \multirow[t]{3}{*}{$75.35(28.47-122.22)$} & \multirow[t]{3}{*}{2} \\
\hline Other & $0.05(0.04-0.07)$ & 2 & $23.61(15.96-31.25)$ & & & \\
\hline Total & $0.15(0.11-0.19)$ & 2 & $64.73(47.92-81.54)$ & & & \\
\hline
\end{tabular}

\section{LITERATURE CITED}

Conover DO, Ross MR (1982) Patterns in seasonal abundance, growth and biomass of the Atlantic silverside, Menidia menidia, in a New England estuary. Estuaries 5:275-286

Dunson WA, Fricano P, Sadinski, WJ (1993) Variation in tolerance to abiotic stresses among sympatric salt marsh fish Wetlands 13:16-24

Dunson WA, Rowe CL (in press) The effects of species manipulation on growth and survival of an assemblage of juvenile estuarine fish. J Fish Biol

Dunson WA, Travis J (1991) The role of abiotic factors in com munity organization. Am Nat 138:1067-1091

Dunson WA, Travis J (1994) Patterns in the evolution of physiological specialization in salt marsh animals. Estuaries 17 $102-110$

Kneib RI (1986) The role of Fundulus heteroclitus in salt marsh trophic dynamics. Am Zool 26:259-269

Kneib RT (1987) Predation risk and use of intertidal habitats by young fishes and shrimp. Ecology 68:379-386

Kushlan JA (1981) Sampling characteristics of enclosure fish traps. Trans Am Fish Soc 110:557-562

Miller JM, Dunn ML (1980) Feeding strategies and patterns of movement in juvenile estuarine fishes. In: Kennedy VS (ed) Estuarine perspectives. Academic Press, New York,

This article was submitted to the editor p $437-448$

Minitab (1989) Minitab reference manual, release 7. Minitab Inc., State College, PA

Morin PJ (1981) Predatory salamanders reverse the role of competition among three species of anuran tadpoles. Science 212:1284-1286

Neter J, Wassermann W, Kutner MH (1990) Applied linear statistical models: regression, analysis of variance, and experimental designs, 3rd edn. Richard D. Irwin Inc., Homewood, IL

Poulin R, Fitzgerald GJ (1989) Early life histories of three sympatric sticklebacks in a salt-marsh. J Fish Biol 34:207-221

Rice WR (1989) Analyzing tables of statistical tests. Evolution 43:223-225

Ricker WE (1979) Growth rates and models. In: Hoar WS, Randall DJ, Brett JR (eds) Fish physiology, Vol 8. Academic Press, New York, p 677-743

Rowe CL, Dunson WA (1994) The value of simulated pond communities in mesocosms for studies of amphibian ecology and ecotoxicology. J Herpetol 28:346-356

Strauss SY (1991) Indirect effects in community ecology: their definition, study, and importance. Trends Ecol Evol 6: 206-210

Weisberg SB (1986) Competition and coexistence among four estuarine species of Fundulus. Am Zool 26:249-257

Manuscript first received: January 25, 1995

Revised version accepted: June 26, 1995 